\title{
CRIAÇÃO DE VALOR AO ACIONISTA
}

Criação de Valor ao Acionista é um tema atual que vem sendo divulgado na literatura pela área financeira. Entretanto sua abrangência é ampla atingindo a estratégia, missão e valores da empresa como é possível observar na lista que se segue elaborada pelo Professor Oscar Malvessi, consultor e professor adjunto do departamento de Contabilidade, Finanças e Controle da FGV-EAESP.

As metodologias com foco na Criação de Valor ao Acionista se diferenciam das demais técnicas de administração, porque habilitam dirigentes e gestores a utilizar, de maneira mais eficiente, os recursos humanos e financeiros disponíveis em seus negócios. Os instrumentos propiciam respostas com alternativas tangíveis, rápidas e claras, demonstrando os caminhos para obter retorno econômico nos investimentos, criando valor ao acionista e demais colaboradores do negócio.

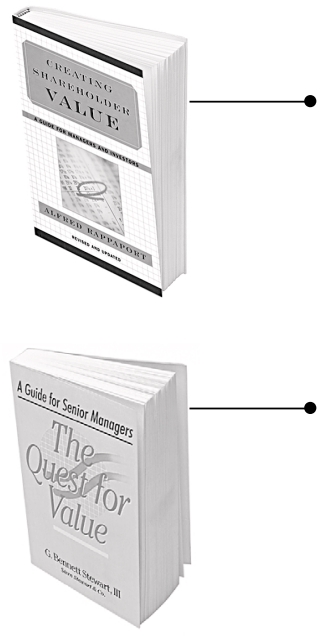

CREATING SHAREHOLDER VALUE: A guide for managers and investors Alfred Rappaport. New York The Free Press, 1998 - revised and updated. 205 p.

Rappaport é um dos pioneiros na apresentação metodológica do conceito de Criação de Valor ao Acionista. Utiliza os conceitos do Lucro Econômico e de fluxo de caixa descontado como instrumentos de avaliação da administração e evolução da performance das empresas. Põe em evidência as deficiências que os conceitos tradicionais de análise apresentam e as diferenças e benefícios proporcionados pelo uso da metodologia de Criação de Valor no estabelecimento de estratégias empresariais e remuneração aos gestores.

THE QUEST FOR VALUE - A guide for senior managers G. Bennett Stewart, III. Harper Business, New York, NY 1991 - $781 \mathrm{p}$.

Neste livro, Stewart introduziu a metodologia do EVA, - Economic Value Added. Desenvolve os conceitos demonstrando as vantagens da utilização da abordagem com foco na Criação de Valor ao Acionista - EVA, para a correta análise do desempenho econômico-financeiro da empresa, quando comparados com os conceitos tradicionais de análise. Demonstra a utilização da metodologia com a aplicação das fórmulas tomando empresas como exemplos. Defende o uso do EVA, para o estabelecimento da remuneração variável e apresenta instrumentos a ser utilizados na definição dos incentivos aos gestores que criem valor ao acionista.

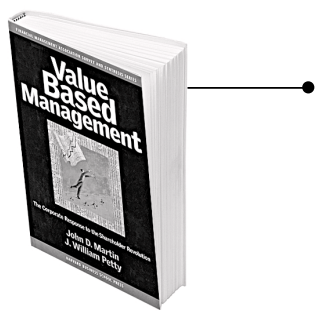

VALUE BASED MANAGEMENT. The Corporate Response to the Shareholder Revolution John D. Martin e J. Willian Petty - Harvard Business School Press, Boston - 2000 - 249 p.

Martin e Petty apresentam os conceitos e instrumentos para a utilização do VBM, metodologia que tem a finalidade de direcionar a administração da empresa para a criação de valor ao acionista. Demonstram que as principais metodologias que defendem a criação de valor ao acionista, utilizam entre outros conceitos, o tradicional método do fluxo de caixa descontado, para avaliar novas oportunidades de investimentos. Apresenta as vantagens e desvantagens com o uso dos métodos e a contribuição para a criação de valor, como também faz a conexão com o sistema de remuneração variável aos gestores.

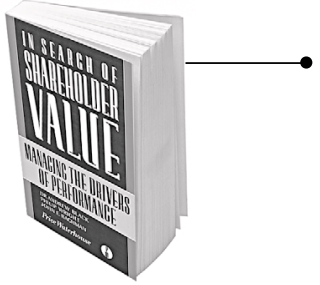

IN SEARCH OF SHAREHOLDER VALUE. Managing the drivers of performance Andrew Black, Philip Wright e John E. Bachman - Pitman Publishing, London 1998 - 292 p.

Os autores descrevem os conceitos da metodologia de criação de valor, usando os direcionadores de valor das atividades como indicadores chaves de medidas, bem como os instrumentos ao qual a criação de valor pode ser mensurada. Apresentam os conceitos para a determinação do custo médio ponderado de capital e demonstram as aplicações da criação de valor em vários setores e países.



THE VALUE IMPERATIVE. Managing for Superior Shareholder Returns James M. McTaggart, Peter W. Kontes e Michael C. Mankins - The Free Press, New York, N.Y. 1994 - 366 p.

Os autores defendem que a administração de valor deve ser direcionada ao objetivo estratégico da empresa para se obter, consistentemente, a criação de valor ao acionista. Demonstram a amplitude conceitual do tema e a necessidade de entender e aplicar os direcionadores de valor nas atividades da empresa e/ou unidades de negócio. Enfatizam o uso da estratégia como instrumento de administração para melhorar a performance da empresa que tem como objetivo a criação de valor ao acionista. 